\title{
Determinación, diferenciación sexual y pubertad en peces
}

\author{
Sex Determination, Sex Differentiation and Puberty in Fish
}

\section{Determinação, Diferenciação Sexual e Puberada em Peixes}

\author{
José Ariel Rodríguez-Pulido ${ }^{1 *}$, Tatiana María Mira-López ${ }^{2 *}$, Pablo E. Cruz-Casallas ${ }^{3 *}$ \\ 1 Biólogo, Msc, (C) PhD \\ 2 Zootecnista, Msc, PhD \\ 3 MVZ, MSc, PhD \\ * Grupo de Investigación sobre Reproducción y Toxicología de Organismos Acuáticos (GRITOX), Instituto de Acuicultura \\ Universidad de los Llanos. Villavicencio, Colombia. \\ Email: jarodriguez@unillanos.edu.co
}

Recibido:11 de octubre de 2017

Aceptado: 03 de junio de 2018

\begin{abstract}
Resumen
En piscicultura es de gran utilidad conocer los procesos de determinación sexual y los mecanismos que permiten la diferenciación sexual, así como el momento en el cual se alcanza la madurez y los individuos son capaces de reproducirse. Estos tres procesos son muy flexibles en peces y no solo dependen de diferentes cascadas de genes, si no que algunos factores ambientales son condicionantes o desencadenantes de ellos. En consecuencia, esta revisión pretende dar una mirada a los últimos avances sobre el tema, particularmente las interpretaciones científicas de los eventos de maduración sexual y sus mecanismos reguladores.
\end{abstract}

Palabras clave: Reproducción, asignación de sexos, madurez reproductiva, evolución, fisiología.

\begin{abstract}
In fish farming is useful to know the processes of sex determination and mechanisms that allow differentiation and the time in which maturation is reached and specimens are able to reproduce, these three processes are very flexible in specimens and not just rely different cascades of genes if some environmental factors are conditions or triggers them. So this review aims to take a look at the latest articles on the subject, scientific interpretations of the events of sexual maturation and their regulatory mechanisms, and review the management of his control.
\end{abstract}

Keywords: Reproduction, sex allocation, reproductive maturity, evolution, physiology.

\section{Resumo}

Na piscicultura, é muito útil conhecer os processos de determinação sexual e os mecanismos que permitem a diferenciação sexual, assim como o momento em que a maturidade é alcançada e os indivíduos são capazes de se reproduzir. Esses três processos são muito flexíveis em peixes e não dependem apenas de diferentes cascatas de genes, mas alguns fatores ambientais condicionam ou acionam esses genes. Consequentemente, esta revisão pretende dar uma olhada nos últimos desenvolvimentos sobre o assunto, particularmente as interpretações científicas dos eventos de maturação sexual e seus mecanismos regulatórios.

Palavras chave: Reprodução, atribuição sexual, maturidade reprodutiva, evolução, fisiologia. 


\section{Introducción}

El grupo más numeroso de vertebrados es el de los peces, al contener alrededor de 28000 especies (Nelson et al., 2016). De estas, aproximadamente 14000 habitan en territorio Colombiano y alrededor de 1500 son dulceacuícolas. Su gran diversidad biológica también se evidencia en la alta diversidad de sistemas y estrategias reproductivas, encontrándose organismos capaces de reproducirse de forma asexual (partenogénesis) o sexual y pueden ser monoicos, dioicos (gonocóricos) e intersexuales (Vandeputte et al., 2007). Se conoce también que existen especies que se reproducen de manera continua o iteróparos o cíclica (anual o estacional), así como otras que solo se reproducen una vez a lo largo de su vida o semélparos (MuñozCueto, 2009). También, el grado de fecundidad de los peces y la duración del periodo reproductivo, varía según la especie.

La aparente complejidad y plasticidad en la biología reproductiva de los peces, establece una estructura poblacional en la cual la proporción de los sexos, no siempre es uno a uno, sino que depende de la asignación de recursos y de la selección natural (Baroiller et al., 1999; Baroiller y D'Cotta, 2001). Generalmente, las hembras gastan grandes cantidades de nutrientes en reservas vitelínicas para la formación y maduración de gametos, en tanto que los machos producen millones de diminutos espermatozoides (Grier y Uribe, 2009; Schulz et al., 2010). El reparto óptimo del recurso energético reproductivo genera estrategias de cuidado parental, competencia por apareamiento y presión de selección; por lo cual, los mecanismos de reproducción en los peces son muy variados, presentándose por lo menos tres modelos diferentes: bisexual o gonocorístico, partenogénico y hermafroditismo (Sadovy y Shapiro, 1987; Penman y Piferrer, 2008; Piferrer y Guiguen, 2008).

\section{Determinación y diferenciación sexual}

Se entiende por determinación sexual los procesos morfo fisiológicos que desarrollan el primordio gonadal toti-potente en los peces y que plantea uno de los problemas más interesantes de los vertebrados, pues no basta la dotación genómica para lograr la definición fenotípica, lo cual se evidencia en que el sexo cromosómico no siempre corresponde con el sexo fenotípico (Joy y Chaube, 2015). Se considera el modelo de determinación sexual genotípica (DGS), como un sistema ancestral monofilético determinado por cromosomas sexuales, sinapomórficos poligénicos asociados a genes autosómicos y determinación sexual ambiental (DES), a periodos sensibles de modificación sexual por factores sociales, lumínicos, de $\mathrm{pH}$ o de temperatura. De esta manera, las gónadas embrionarias partiendo de un rudimento común, conformado por células somáticas de la cresta gonadal y células primordiales gonadales, pueden desarrollarse en dos órganos adultos distintos, ovarios o testículos, afectando la estructura demográfica de la población (Budd et al., 2015).

La diferenciación sexual es un proceso muy flexible, en donde se involucran numerosos eventos fisiológicos que culminan con la morfogénesis de un ovario o de un testículo, a partir de una gónada indiferenciada (Heule et al., 2014). Esta se inicia con una capa delgada de tejido conjuntivo, en el blastodisco sobre el vitelo y que durante la gastrulación forma las crestas germinales, a las cuales llegarán las células germinales (PGC), procedentes del plasma polar, en los surcos de segmentación (Labbe et al., 2017).

\section{Cresta genital}

Engrosamiento del mesodermo que a diferencia de como ocurre en tetrápodos, según Devlin y Nahagama (2002) en peces participa muy poco el mesonefro, sin desarrollar ni conductos de Müller ni de Wolff; en su lugar, los primordios gonadales, presentan crecimiento somático que formará una cavidad sin diferenciación sexual, siendo compatibles estos desarrollos con un ovario temprano y será la presencia de estradiol, que junto al mayor número de células germinales que lleguen a la cresta genital, las que determinarán si se consolida como un ovario o si por la actividad de la hormona antimulleriana (AMH/ MIS), la inhibición de la aromatasa y la producción de andrógenos, la cresta se transformará en un testículo (Santi et al., 2016). Según Piferrer (2009) consideró que morfológicamente el sistema reproductor relacionado con el riñón, en los ciclóstomos el conducto de Wolff conduce orina y la gónada se abre hacia el celoma, permitiendo la salida de gametos por el poro urogenital conectado al conducto de Wolff. En hembras de teleósteos se forma un ducto de Müller, que se une con el conducto de Wolff en el seno urogenital, mientras que en los machos, el conducto de Müller desaparece y los espermatozoides usarán el conducto de Wolff, entretanto que la orina usa un conducto accesorio.

\section{Migración de las células germinales primordiales (PGC)}

En medaka (Oryzias latipes), la migración de las células primordiales ocurre durante el desarrollo embrionario temprano, hacia el final de la gastrulación (Finn-Arne et al., 2014). Así mismo, en el pez cebra (Danio rerio),

Determinación, diferenciación sexual y pubertad en peces 
desde la primera hora posfertilización, las PGC conforman un grupo de células polares vitelínicas (plasma polar) que se relaciona con el mRNA del gen vasa y que junto con incrementos de la fosfatasa alcalina, protegen a las células germinales de los factores de transcripción de las restantes células somáticas. Esta represión mantiene la pluripotencialidad de las PGC, que durante la gastrulación tardía, migran desde al arquenteron posterior, hacia la cresta genital por los surcos de segmentación (Wong y Zohar, 2015).

El proceso se inicia con la formación de las gónadas, a partir de los primordios genitales que se forman desde la gastrulación temprana y en asocio con el mesonefro, las células primordiales migran desde el endodermo asociado al saco vitelino. Su et al. (2014), encontraron que los genes nanos, dead end y vasa, asociados a la migración de las células primordiales, se expresaron seis horas pos fertilización en carpa (Cyprinus carpio) y fueron determinantes al bloquear su expresión y obtener animales estériles o con maduración sexual tardía, igualmente se encontró para el bagre de canal (Ictalurus punctatus) depleción de las células germinales (Su et al., 2014, 2015).

Tzung (2015) observó en Danio rerio, que si el número de células primordiales que alcanzan la cresta genital son inferiores a cuarenta y éstas se localizan en la zona medular de la cresta genital, darán origen a un testículo, pero si el número de células primordiales es mayor, se localizan en la corteza del primordio gonadal y conformarán un ovario. Esto puede ser concomitante con altos niveles de estrógenos, que favorecen la expresión de los genes fox 12, fst, fsh, y bmp 4 y la represión de otros genes como los dmrt, nrob sox 9 y pax $2 \mathrm{a}$, como se obtuvo en los intentos de feminización de alevines de bagre rayado (Pseudoplatystoma fasciatum) (Su et al., 2014).

En tilapia nilótica (Orechromis niloticus), se observó que la migración de las células germinales primordiales (capaces de hacer meiosis) se hace desde la región vitelina en el espacio sincitial del periblasto y las paredes del tubo digestivo, hasta alcanzar la cresta o primordio gonadal y se asocia fuertemente a la periferia del futuro ovario y de manera decidua a la parte media del futuro testículo (teoría cortico-medular). Pérdidas de células germinales o factores xenobióticos pueden generar intersexos y generar individuos con sexo indeterminado (Kneko et al., 2015). Paralelamente, se conforma el eje de control reproductivo cerebro-hipotálamo-hipófisisgónadas, haciéndose evidente el papel de las hormonas FSH (hormona foliculoestimulante) y LH (hormona luteinizante) en la definición sexual a las dos semanas de desarrollo (Devlin y Nahagama, 2002).

\section{Epigénesis de la determinación sexual}

Como se mencionó anteriormente, la determinación sexual está mediada por la dotación cromosómica del individuo. Los cromosomas en los peces son reducidos, generalmente homomórficos y por ello se han encontrado genes maestros generalmente asociados con los cromosomas sexuales, como el gen dmy, equivalente al gen sry reportado para mamíferos. Dicho gen, presente en el cromosoma $\mathrm{Y}$, propio de los machos heterogaméticos. En peces suele utilizarse determinación sexual monogénica con machos heterogaméticos (XY) u homogaméticos (ZZ), hembras heterogaméticas (ZW) u homogaméticas (XX), como son los casos de tilapia nilótica y medaka, donde la expresión del gen dmy se registró entre los 5-6 días pos-fertilización (dpf), pero sólo hasta los setenta días fueron encontrados dimorfismos en los numerosos receptores celulares de la hipófisis a FSH b, de hembras, en tanto, que no se registraron para machos (Horie et al., 2014). También se han observado condiciones de hermafroditismo natural, secuencial o simultáneo (Matsuda y Sakaizumi, 2016), como en el caso de la lubina, que tiene un carácter poligénico.

Los avances en genética molecular, demuestran la plasticidad fenotípica a causa de la variación en los genes determinantes y la posible relación epigenética en la determinación sexual de los vertebrados (Metzger y Shulte, 2016). También han sido identificados nuevos genes candidatos determinantes para otros vertebrados citados por Matsuda (2016) tales como: dm-w de la rana de uñas africana, dmrt1 y factor de transcripción relacionados con el mab-3 en las aves, amhy en el pejerrey patagónico (Odontesthes hatcheri), sdy en la trucha arco iris (Oncorhynchus mykiss), en oryzia (Oryzias luzonensis) gsdfy, Amhr2 en tres peces globo (Takifugu rubripes, T. pardalis, y T. poecilonotus) y el sox3y en Oryzias dance (Ikegami et al., 2014).

En tilapia nilotica, además de la transformación de la testosterona a estradiol (Tzung et al., 2015), mediante la aromatasa, como factores de definición del sexo se encuentran asociados 17 genes, incluyendo el sox 9 y el gen de la antimulleriana (AMH). Estos dos últimos genes sólo se encontraron en machos y estuvieron activos desde el día 16 al 25 pos fertilización (dpf). Esto supone una condición inicial ginogénica, que se modifica por acción hormonal o por genes que se encienden o apagan, haciendo la ya mencionada formación temprana del ovario y la determinación tardía del testículo (Devlin y Nagahama, 2002).

Genes dmrt (Minkina et al., 2014) y genes sensibles a la temperatura, actúan sobre las vías moleculares durante la diferenciación sexual en los teleósteos, modifi- 
cando los perfiles de expresión temporal de cyp19a1a y FOXL2, dos genes que se asocian con la conformación de ovario y dmrt1 y AMH, asociados al desarrollo de testículos, y a la determinación del sexo por factores ambientales (Devlin y Nahagama, 2002). En hembras homogaméticas $(X X)$ de tilapia nilótica se analizaron los genes que en etapa termo sensible permiten la diferenciación sexual, independiente de la dotación cromosómica. Las expresiones de los genes amh y dmrt1 son reguladas por la temperatura, entre los días 13 a 15 pos fertilización. Los niveles de dmrt1 fueron tres veces mayores bajo temperaturas altas, mientras que los niveles de AMH fueron ligeramente mayores, lo anterior sugiere una regulación por genes foxl2, cyp 19a1a y la evolución de genes de la familia cromo box (Liu et al., 2017).

Otros genes, como dyr hm, en un proceso evolutivo permiten que Oryzias latipes (Matsuda y Sakaizumi, 2015) determine su sexo. Los análisis de la distribución de los tejidos revelaron que todos los sistemas de transcripciones en las cuatro kisspeptinas se expresaron tanto en cerebro, como en gónadas; sin embargo, kiss2 fue la transcripción predominante en las gónadas y la única detectada en los huevos ovulados. El análisis de expresión ontogénica de kiss2, en las gónadas de juveniles de bacalao negro (Notothenia microlepidota) demostró que los niveles son bajos durante la diferenciación sexual, pero aumentaban con el tamaño del pez y el desarrollo gonadal. Los aumentos dramáticos en kiss2 marn se produjeron durante el crecimiento de los ovocitos primarios, mientras que los niveles se mantuvieron relativamente bajos en los testículos. La hibridación in situ reveló que kiss2 marn se localiza en el citoplasma de los ovocitos durante la fase perinucleolar (Fairgrieve et al., 2016).

Los genes asociados, que codifican para la hormona antimulleriana, se encuentran tanto en machos como en hembras (Pfennig et al., 2015) en las células de sertoli o en las de la granulosa, respectivamente. Lo anterior, no es condición suficiente en la diferenciación. Dado que la determinación es anterior y está controlada por una cascada de genes, (epigenética gonadal) en peces (Ribas et al., 2016). Se demostró que la hipermetilación del promotor cyp 19a1a se relaciona con ovotestis y testículos en anguila y dnmT1 en ovarios de rodaballo (Scophthalmus maximus) (Ribas et al., 2016). El colesterol pasa al interior de la mitocondria, por la proteína star (transportadora de colesterol) y depende de la enzima citocromo P450 aromatasa, producto del gen cyp 19 a1a, y el bloqueo de la enzima masculiniza al individuo. En pez cebra, se encontró que el gen diferenciador para machos es dmrt1, aunque se han encontrado más genes asociados, como una cascada de diferentes genes que se expresan durante la definición sexual (Li et al., 2014).

La cascada molecular que envuelve la determinación de testículo en pejerrey (Odontesthes bonariensis) no sólo incluye los genes (amh, dmrt1 y sox9) asociados a las células de sertoli o los asociados a las células de leydig (nr5a1 y sf1) sino que los genes cyp11a1 y cyp 11b1 que son termo sensibles y su expresión diferencia el sexo a temperaturas bajas $\left(17^{\circ} \mathrm{C}\right)$ hembras y en altas temperaturas $\left(29^{\circ} \mathrm{C}\right)$ machos durante el periodo termo-sensible. La condición diferenciada de testículo, puede incluir la supresión de los genes de aromatasa (cyp19a1a, cyp 11), la inhibición de su actividad o el bloqueo de la receptividad a estrógenos. Dicha actividad se encontró no sólo en peces sino en anfibios y su actividad se registra a nivel cerebral (Coumailleaur et al., 2015). Aún más, se evidenció en bocachico Prochilodus argenteus que no sólo hay inhibición de la aromatasa por elevadas temperaturas sino que se generan bajos niveles de estradiol, que además de causar pérdidas en la ovulación, los ovocitos no presentan vitelogénesis, dado que el índice gonadosomático está estrechamente relacionado con la vitelogenina y la proliferación celular durante la foliculogénesis, mediadas por cathepsina $d$, sin embargo, las altas temperaturas han favorecido la apoptosis y la atresia, lo anterior denota el riesgo del calentamiento global (González et al., 2015).

\section{Pubertad}

Entendida la pubertad como el proceso por el cual un animal diferenciado sexualmente e inmaduro adquiere la habilidad para reproducirse por primera vez, después de una fase de crecimiento juvenil (Carrillo et al., 2015), la cual incluye una serie de complejos sistemas neuroendocrinos que culminan con la producción de gametos y hormonas (Almeida et al., 2016) para asegurar la perpetuación de la especie. La pubertad en los peces se caracteriza por el desarrollo de las estructuras necesarias para la reproducción (Escobar et al., 2016), así como de las características secundarias tales como órganos intromitentes, orlas, espículas, coloración nupcial, entre otras.

\section{Definición sexual en especies monoicas}

Este proceso se da por determinación sexual que puede ser genómica (DSG) o determinada por el ambiente (DST), finalmente, será el número de células primordiales germinales (PGC) que lleguen a la cresta genital y la expresión de numerosos genes (epigenéticos), los que definen si se forma un ovario o un testículo (Devlin y

Determinación, diferenciación sexual y pubertad en peces 
Nagahama, 2002). En el rodaballo, de 56 posibles genes se encontraron 44 relacionados con la determinación de hembras y 12 con machos (Ribas et al., 2016). Durante la maduración de las células germinales y la diferenciación de las de soporte, en las especies monoicas, el testículo diferenciará las espermatogonias que junto con las células de sertoli, conforman un cisto testicular, en cuyo intersticio proliferan las células de leydig, los fibroblastos, las células peritubulares y capilares sanguíneos, entre otros.

En las hembras las oogonias proliferan por mitosis para convertirse en ovocitos y las células de la granulosa que lo acompañan se convertirán en células pre foliculares que bajo acción de la inhibina y activina, regulan el desarrollo de ovocitos, que al relacionarse con niveles de hormonas circulantes, MIS (esteroides inductores de maduración), darán inicio a la reclusión, vitelogénesis y maduración de ovocitos. Para muchas especies se ha reportado una pubertad prematura y generalmente son los machos los que en el primer año la alcanzan, sin producir un volumen espermático adecuado, dando origen a una gametogénesis incompleta o desarrollo tentativo (Devlin y Nagahama, 2002).

\section{Ciclo reproductivo}

Considerando que las diferentes fases reproductivas son especie-específicas pero influenciadas por condiciones ambientales, tales como temperatura del agua, profundidad, duración del día, fase lunar, por las condiciones bióticas, por recursos alimentarios, competencia, disponibilidad de apareamiento, estructura del hábitat. Así, el ciclo de vida pasa de la fase inmaduro (Almeida et al., 2016) a la fase de maduración, durante la pubertad (Alves et al., 2014; Guzmán et al., 2015). En el ciclo de maduración las gónadas pasan por las fases de: desarrollo, capacidad de desove, regresión o regeneración.

Las especies semélparas (salmón- anguilas) no tienen el ciclo completo y por ello no hay fase de regresión dado que generalmente mueren después de la reproducción (Alves et al., 2014). En tanto que las especies iteróparas cumplen el ciclo.

\section{Cambios en el eje cerebro hipófisis gónadas (CHG)}

El control jerárquico de genes, que activan o no la pubertad están altamente conservados en la evolución, son extremadamente sensibles a señales internas y externas. Los genes de las kisspeptinas y de su receptor kiss 1/gpr54 que están encargados de activar directamente a las neuronas GnRH (hormona liberadora de gonadotropina) y potencian la liberación de gonadotrofinas (Guzmán et al., 2015; Carrillo et al., 2015).

Si bien la pubertad no se inicia como consecuencia de un único factor y hasta hace poco se consideraba que, era originada por, los pulsos nocturnos de la GnRH como gatillo para desencadenar la pubertad precoz (control central) (Gopurappilly et al., 2013) hoy se sabe que hay un conjunto de factores epigenéticos, señales metabólicas, estrés y estímulos ambientales, que son los determinantes para activar el eje CHG (cerebro- hipófisis - gónadas) y alcanzar la pubertad. Así como el bloqueo a la secreción de gonadotropina inhibitoria GnIH (hormona inhibitoria de gonadotropinas) (Biswas et al., 2015).

En mamíferos, los pulsos aún en la vida fetal de GnRH desencadenan pulsos de las gonadotrofinas que persisten hasta el nacimiento, para luego mantener un nivel basal hasta el inicio de la pubertad cuando factores metabólicos como insulina, grhelina, galanina, glocosa, ácidos grasos y leptina, que indican la condición energética del individuo (Chun-Wei y Koopman, 2014). Además, factores genéticos y moleculares como kisspeptinas su receptor gpr54, el gen kal2 y el receptor para el factor de crecimiento de fibroblastos (fgfr) y otros factores internos como niveles de acetilcolina, catecolaminas, GABA (ácido gamma-aminobutírico), asociación con taquiquinina, prostaglandinas y serotonina permiten la secreción pulsátil de GnRH que activa la síntesis, también pulsante de FSH y LH, que permiten la diferenciación sexual temprana (Zhang et al., 2015).

Por lo tanto, la información sobre los patrones epigenéticos de la kisspeptina-permite entender la regulación del eje neuro endocrino, el control en los sistemas de GnRH y GnlH en el cerebro y puede proporcionar información valiosa sobre la coordinación general (Lomniczi et al., 2015). El momento de la señalización neuroendocrina durante la pubertad en peces implica el silenciamiento de PcG (proteínas del grupo polycomb) para su inactivación o la transcripción de proteínas trxG (trithorax), básicamente activados por kiss 1, en el centro de los núcleos arcuato y preóptico, donde también reside el centro de estímulos ambientales como la luz (melatonina), la nutrición (leptina) y disruptores endócrinos (dopamina). Por ello, estímulos como el reloj circadiano, nutrición, el ambiente, estrés, entre otros, a través de vías epigenéticas regulan el comienzo de la reproducción, inclusive factores como las ferohormonas, pueden influir en la actividad de las kisspeptinas demorando la pubertad (Seminara et al., 2003; de Roux et al., 2003). 
En peces se ha encontrado también que la melatonina, por su carácter lipofílico, es un potente candidato en la regulación de la maduración sexual, mediante ciclos diarios que desencadenan acciones antioxidantes en la mayoría de células, pero fundamentalmente en el eje CHG e indiscutiblemente es factor desencadenante de la pubertad (Devlin y Nagahama, 2002).

Las neuronas kisspeptinas, son blancos directos de hormonas esteroidales provenientes de la gónada y que logran una retroalimentación negativa o positiva (Carrillo et al., 2015, Chi et al., 2014). El sistema kiss/ gpr54 se reporta como fundamental en controlar la pubertad y estar influenciados por la luz como en lubina Dicentrarchus labrax con alto grado de conservación evolutiva, ya que los mismos mecanismos de transcripción e inhibición se ha reportado en mamíferos (Escobar et al., 2013). El periodo crítico de exposición lumínica es específico para cada especie (Hussain et al., 2015) la regulación fótica de la pubertad, permite que peces expuestos a luz continua o con un mes de luz continua durante el periodo fotosensible inhiban la maduración y logren alcanzar mayores tallas (Carrillo et al., 2015).

Se sugiere que los ritmos circadianos determinan los ritmos multi estacionales dado que el máximo desarollo gonadal depende de la cantidad de $\mathrm{FSH}$ y $\mathrm{LH}$ liberada. Picos de FSH y antimulleriana (AMH) favorecen la maduración temprana de machos (Pfennig et al., 2015) y los picos nocturnos de LH (en oscuridad) permiten la maduración y la espermiación, estos relojes circadianos son dependientes de la melatonina o de receptores de galanina (grhelina) (Martins et al., 2014). La galanina es un neuropéptido reportado para mamíferos como regulador de las funciones reproductivas, nocicepción, aprendizaje, ingesta de alimentos (Carrillo et al., 2015, Mazón et al., 2015).

\section{Crecer o reproducirse, mecanismos de compensación (trade off)}

En mamíferos se ha descrito como se integra el balance energético, las funciones somáticas y la reproducción. Así, las señales enviadas desde el sistema digestivo como la grelina (antagonista de leptina) permiten los depósitos grasos, en tanto que la leptina, hormona secretada por los adipocitos, funciona como factor de saciedad, controla el peso y en acción sinérgica con el neuropéptido y (npy) dispara la zona-génesis. La leptina no solo indica el estado de las reservas lipídicas del animal que controlan la saciedad, sino que influye directamente en la función reproductiva, así, en roedores el sistema kisspeptina actuando sobre el núcleo premamilar ventral, se asocia con la leptina que actúa sobre la gónada como una señal importante de suficiencia energética (Schaefer y Wuertz, 2016).

Una condición magra y de bajo peso denota menores concentraciones de kisspeptina en el núcleo arcuato del hipotálamo y el organismo desarrolla hipogonadismo, aumentos de leptina provocan incrementos de kisspeptinas y de su receptor gpr54 logrando anticipar la pubertad (Liu et al., 2010). El mARN que codifica el receptor de leptina LEPR (ob-Rb) se detecta en el núcleo arcuato hipotalámico donde actúan las kiss. La leptina secretada por el tejido adiposo, se considera como regulador de la sensación de saciedad y por ello regulador del peso, las mayores concentraciones de leptina estimulan la liberación de $\mathrm{FSH}$ y $\mathrm{LH}$ en truchas (Weil et al., 2003).

La leptina, una citoquina secretada por el tejido adiposo, altamente conservada durante la evolución y clonadas en peces desde 2005, en la cual se ha encontrado que si bien controlan el balance energético en peces sedan otras rutas como la actividad de la grelina (Gorissen y Flik 2014, Park y Ahima 2015). Igualmente, la leptina está relacionada con los niveles de vitelogenina en sangre, los cuales pueden ser usados como indicadores tempranos de la pubertad y no solo por los incrementos en los índices gonadosomáticos (Ferrandino et al., 2015). En peces, genes ortólogos de leptina se encuentran en regiones hipotalámicas (Escobar et al., 2016) y en periodos largos de ayuno aunque no se inhiba el comienzo de la pubertad si se puede asociar a disfunciones en la maduración, bajos índices gonadosomáticos e incrementos de células apoptóticas en lubina (Escobar et al., 2014) pero si bien estas dietas extremas retrasan la pubertad no hay obstrucción completa y aun con bajos niveles de GnRH y GTH se en cuentan machos con bajas tasas de espermiación (Escobar et al., 2016).

En los peces, la edad y el tamaño para la pubertad son especie-específicos y sus funciones metabólicas han coevolucionado de acuerdo a las condiciones ambientales (Carrillo et al., 2015) marcadamente estacionales y generalmente en aguas altas, por la alta oferta de alimento son propios de una ingesta alimenticia máxima, permitiendo un periodo de crecimiento rápido. El crecimiento somático disminuye en gran parte por la falta de alimento y permite la movilización de grasas hacia las gónadas para completar la maduración (vitelogénesis) e iniciar las migraciones reproductivas, este estatus nutricional y las condiciones ambientales modulan el eje reproductivo (Devlin y Nagahama, 2002). En teleósteos, se reportan dos isoformas de leptina, siendo leptina-A y leptina-B respectivamente, aunque gran parte de su función sigue siendo desconocida 
(Gorissen y Flik, 2014) son responsables del acúmulo energético y control del apetito, pero otras investigaciones han demostrado que la expresión de ARNm de leptina-A es significativamente más alta que en los machos, diferente de la leptina-B en las hembras. Aun así, la expresión de la leptina-A está asociada a los niveles de estradiol, siendo indispensable en machos prepuberes para alcanzar la maduración (Chen et al., 2016). Exposiciones prolongadas durante el ayuno resultan en apoptosis y atresia vía reducción de IGF (factor de crecimiento insulínico) y FSH en los folículos, reducción de los niveles de esteroides y de los genes que los codifican (Franz et al., 2016).

El número creciente de moléculas implicadas en los trastornos de la alimentación, obesidad, anorexia y termorregulación, al igual que en mamíferos se ha comprobado la existencia de las orexinas o hipocretinas que son dos neuropéptidos de la superfamilia de péptido incretina (polipéptido inhibidor gástrico GIP y polipéptido semejante al glucagón GLP) (Busber et al., 2005). En los núcleos laterales hipotalámicos se encuentran fibras productoras de orexinas- hipocretina (López et al., 2014) que como en mamíferos están ligadas a la actividad, reflejos de huida y que en mamíferos se asocian a disfunciones de la vigilia (sueño).

El umbral metabólico tiene claro impacto en la pubertad de hembras de ayu Plecossus altivelis, relacionados con los niveles de estradiol y leptina, pero en machos, se asoció a la territorialidad y selección de pareja referencia (Sánchez-Garrido, 2013). Sin embargo, en roedores y otros mamíferos las condiciones mórbidas por mayor concentración de leptinas bloquean la secreción de esteroides sexuales y por ello en obesos se da un desarrollo hipogonadal (Hussain et al., 2015; Diemer et al., 2014).

Leptina y IGFs actúan como hormonas modulando las kisspeptinas, es así como peces precoces comienzan su maduración a menores tallas desde que cuenten con depósitos grasos, los cultivos intensivos, generan más depósitos grasos y por ello más peces son precoces y exhiben mayores concentraciones de FSH y $\mathrm{LH}$, que los homólogos no precoces, mostrando correlaciones entre el tamaño del cuerpo y las reservas energéticas (Carrillo et al., 2015). La leptina, reguló positivamente los niveles de insulina y factores de crecimiento, en híbridos de striped bass (Morone saxatilis) (Gorissen y Flik 2014) sugiriendo que la leptina coordina el crecimiento somático, las hormonas del crecimiento y puede ser estimulada por los estrógenos (Wong y Zohar 2015; Baroiller et al., 2014).

\section{Inicio de la pubertad}

En algunos peces se ha encontrado que la función reproductiva prima sobre las otras y que aun en condiciones de restricción alimentaria los peces intentan reproducirse consumiendo parte de sus reservas (Carrillo et al., 2015). Según Fairgrieve (2016) en el pez sable (Anoplopoma fimbria) se encuentran dos tipos diferentes de kisspeptinas, Kiss 1 y su receptor gpr54 1 que actúan comenzando la pubertad y Kiss 2 y su receptor gpr54 2 que actúan cuando se presenta la espermiación y ovulación (Plant, 2015).

Como se ha reiterado la fisiología de los peces dependen de las condiciones ambientales, ciclos circadianos y temperatura ambiental (Wang et al., 2014). Así el sistema kiss/ gpr54 está influido por la luz y son los fotoperiodos cortos de tres mes (6 o 7 son los naturales) los que desencadenan la maduración en lubina por descargas de melatonina, que estimulan la expresión de kisspeptinas, las que a su vez permiten la liberación de GnRH y ocasionan pulsos nocturnos de LH y con ello se alcanza una pubertad temprana (Devlin y Nagahama, 2002).

La retroalimentación está mediada por los esteroides sexuales, es así como la testosterona actúa inhibiendo la FSH hipofisiaria y con ello se logra la renovación de espermatogonias y oogonias (Cain y Pryke, 2017) sumado a esto, la $11 \mathrm{Kt}$ (11-Cetotestosterona) estimula la división de las células de sertoli contribuyendo con la espermiación, situación que fue encontrada en peces inhibidos por estar el luz permanente, pero que posteriormente, al recibir dosis de $11 \mathrm{Kt}$ lograron la espermiación, sin olvidar el papel fundamental de la aromatasa.

Así mismo, la ovulación está precedida de cambios hormonales es así como los niveles de 17B estradiol y testosterona se relacionan con la pubertad (Devlin y Nagahama, 2002) e inclusive por la presencia de xenobióticos que pueden modificar el sexo o la pubertad (Luzio et al., 2016) o por manejo de hormonas recombinantes (Mazón et al., 2015).

\section{Prospectiva en el manejo de la pubertad}

En ambientes naturales la oferta alimentaria no es permanente y está limitada provisión de recursos a forzado estrategias evolutivas que permiten compensar el destino final de las reservas energéticas de los peces, en consecuencia se establece un equilibrio o sistema de compensación (trade off) entre funciones, se crece o se reproduce, se establece o se migra (Trippel et al., 2014). En condiciones de cultivo, generalmente la oferta alimentaria es permanente y por ello los peces 
así mantenidos rápidamente acumulan gran cantidad de lípidos y con ello anticipan la pubertad, el inicio de la maduración retrasará el crecimiento, los hará más susceptibles a enfermedades y aumentarán las lesiones por ataques, ante todo en machos y especies territoriales (Dutil y Lambert, 2000; Descamps et al., 2009) razón por la cual en otras latitudes se busca bloquear o retrasar la maduración y así obtener mayor rendimiento en carne, como lo logrado con bloqueos del fotoperiodo en lubina (Yildirim y Vardar, 2015).

De otra parte para productores de alevinos o de ovas puede ser más importante anticipar la pubertad y lograr parentales en menor tiempo (Almeida et al., 2016). El control de la maduración y la modulación ambiental es esencial en la acuicultura para obtener mayor rentabilidad, ya sea porque mediante modificaciones ambientales o terapias hormonales se atrase o adelante la maduración gonadal.

No solo los factores endógenos controlan la reproducción sino que los factores ambientales desencadenan o activan sistemas hormonales que inhiben o la estimulan, la reclusión ovárica y la maduración, como ya se habló del fotoperiodo de la temperatura (Devlin y Nahagama, 2002; Mazzeo et al., 2014) fases lunares o inclusive la duración de las mareas (Rhody et al., 2015) y factores estresantes que rompen la homeostasis y desencadenan cascadas de hormonas, que como las catecolaminas, citoquinas, son capaces de bloquear la maduración gonadal. Lo mencionado anteriormente, fue observado por Barcellos et al. (2014) en bagre sapo (Rhamdia quelen), especie en la cual la pubertad fue afectada por factores estresantes como la pesca.

Probablemente, son las temperaturas y no el fotoperiodo uno de los factores ambientales más poderosos en modular la expresión génica mediante mecanismos epigenéticos, encontrándose que altas temperaturas favorecen la apoptosis de las células germinales y disminuyen significativamente la actividad de la aromatasa, degradan hormonas o factores termolábiles e inclusive alteran y permite la diferenciación sexual a machos (Pandit et al., 2015) así se propone mantener peces indiferenciados a determinada temperatura y obtener alevinos de un solo sexo (Santi et al., 2016; Wang et al., 2014). En oryzias, mediante el manejo de alta temperatura $\left(32-34^{\circ} \mathrm{C}\right)$ así mismo, mecanismos para eliminar las células germinales primordiales o impedir su migración a las crestas genitales o mediante modificación genética y transgénesis producir peces estériles, pueden ser las respuestas al aumento de la acuicultura (Wong y Zohar, 2015).

\section{Aplicaciones en acuicultura}

\section{Manejos hormonales}

Dados los mayores crecimientos en hembras de muchos bagres se ha intentado feminizar, mediante el uso del $17 \beta$ estradiol a bagre rayado desde los 30 días pos fertilización, hasta los 240 días. Encontrando que en las hembras se diferencian primero que los machos 120 -180 dpf (días posfertilización) y los machos 180$240 \mathrm{dpf}$, sugiriendo que la hormona debe ser suministrada antes de los 39 días posfertilización cuando seda todavía el periodo sensible al cambio (Valentin, 2013).

Por mayores crecimientos y el poder controlar las poblaciones de tilapias en un estanque de ceba, hay gran interés por los acuicultores, para obtener poblaciones de peces mono sexo y por ello se recurre a la reversión sexual mediante la masculinización de alevines indiferenciados suministrándoles $17 \alpha$ Metil testosterona. Procedimiento semejante en pejerrey recientemente se logró masculinizar un 90\% de peces usando $5 \alpha$ dimetil testosterona DHT (Wang et al., 2014).

En pez cebra las células germinales pueden mantener el fenotipo, así, cuando las oogonias desaparecen en el individuo, este puede tomar el fenotipo de macho, haciendo que un derivado de las células primordiales iniciales como ovocitos, que actúa sobre la gónada bipotencial, determinaría la condición de hembra y si estas son removidas entonces se define como macho. Denotando una condición inicial hacia el fenotipo de hembra, que debe ser mantenido por señales de células somáticas, la presencia de la aromatasa (expresión de cyp19 1a1a) y células germinales y hormonas (Piferrer y Blázquez, 2005).

\section{Manejos de temperatura}

En tilapia nilotica también se han reportado como durante el periodo termo sensible, incubaciones llevadas hasta las $20 \mathrm{hpf}$ (horas posfertilización) a temperaturas superiores a los $33^{\circ} \mathrm{C}$ dieron como resultado mayor proporción de machos (Baroiller et al., 2009). En bagre africano (clarias gariepinus), se determinó que a partir que desde el sexto día hasta el octavo día, hay un periodo termo sensible y si los alevines se someten a temperaturas cercanas a los $36^{\circ} \mathrm{C}$ se obtienen poblaciones de machos (Santi et al., 2016).

En vertebrados, la temperatura es el factor determinante más común de sexo, y la variación estacional de la temperatura (Wang et al., 2014) sirve como una señal temporal de la calidad del medio ambiente y pude establecer la temporada de crecimiento. Algu- 
nos ambientes, carecen de fuertes fluctuaciones de temperatura y otras señales, especialmente fotoperiodo, pueden proporcionar un indicador más fiable de la temporada, de esta manera, en bajas temperaturas y días más cortos se producen mayor número de hembras (Brown et al., 2014).

Manejos combinados de hormonas y regulación de temperatura pueden modificar el sexo o inclusive andrógenos o estrógenos presentes en aguas servidas pueden alterar la determinación sexual u originar alteraciones reproductivas (Luzio et al., 2016) e inclusive originando individuos intersexos por disrupción endocrina. Además, la masculinización inducida por el estrés térmico se puede considerar como una consecuencia de la inactivación del cortisol y la síntesis simultánea de $11 \mathrm{Kt}$ y discutiendo esto como un posible mecanismo de masculinización inducida por diferentes tipos de estresores ambientales. Así mismo la incorporación de estrógenos modifica el sexo (Tokarz et al., 2015).

\section{Manejo de híbridos}

Los ejemplares triploides de lubina son estériles, mejorando sus posibilidades de cultivo al proteger la biodiversidad, los aparentes machos, mostraron testículos con espermatocitos y espermatidas pero nunca se encontraron espermatozoides funcionales (AlcántarVázquez, 2016). En las hembras, los ovarios fueron rudimentarios con oogonias y pocos ovocitos previtelogénicos dispersos. En ambos sexos, las lecturas de GnRH fueron semejantes y con valores próximos a las de los peces diploides, pero los niveles de testosterona y estradiol nunca alcanzaron valores cercanos a los encontrados en ejemplares diploides. Así, se demuestra que hay una esterilidad funcional en triploidía que además, incluye la apoptosis de células germinales en los triploides de rodaballo. La triploidía suele asociarse a la baja viabilidad y altos porcentajes de deformaciones en el individuo heterogametico, encontrando que de 56 genes involucrados en la determinación 44 se asocian con el fenotipo de hembras incluyen la expresión de la aromatasa (cyp 19 a11a) (Cnaani et al, 2013; Ribas et al., 2016).

\section{Manejo de peces estériles}

La producción de peces carentes de células germinales han originado peces estériles capaces de crecer pero no aptos para la reproducción, pues únicamente se formarían los primordios gonadales con tejido conectivo, lo anterior se ha logrado en pez cebra (Tzung et al., 2015) y en bagre de canal (Su et al., 2015). Una de las técnicas utilizadas para generar individuos estériles es denominada vivo 4, en la cual, por inmersión de huevos recién fertilizados en oligoguanidina dendrimérica con un núcleo de triazine, es capaz de atravesar el corion y llevarlo al embrión, posteriormente y por un tiempo de una o tres horas lograron 100\% de esterilidad para pez cebra, convirtiéndose en una de las mejores posibilidades para inducir de forma masiva esterilidad al impedir la formación de gónadas, así, los ejemplares tratados solo exhiben tejido conectivo y tejido adiposo, como un delgado filamento, sin desarrollar gónada alguna (Wong y Zohar 2015).

\section{Conclusión}

La determinación y la diferenciación sexual en peces ha sido un tema complejo, aunque existen grandes avances en las técnicas empleadas, se hace necesario su aplicabilidad en especies neotropicales, ya que muchas de ellas son promisorias para la acuicultura. De tal manera que se podría vislumbrar en mayor profundidad algunos aspectos que permitan generar entendimiento sobre las características sexuales en las especies y así establecer relaciones filogenéticas.

\section{Referencias}

Alcántar-Vázquez JP. Fisiología de los peces triploides. Lat Am J Aquat Res. 2016;44(1):1-15.

Almeida FL, Lopes JS, Crescencio R, Izel ACU, Chagas EC, Boijink C. Early puberty of farmed tambaqui (Colossoma macropomum): Possible influence of male sexual maturation on harvest weight. Aquaculture. 2016;452:224-232.

Alves AL, Souza Varela E, Vitti Moro G, Ganeco Kirschnik LN. 2014. Riscos genéticos da produção de híbridos de peixes nativos. Documentos / Embrapa Pesca e Aquicultura, ISSN 2318-1400; 3.

Barcellos LJ, Woehl VM, Koakoski G, Oliveira TA, Ferreira D, da Rosa JGS, Fagundes M. Puberty influences stress reactivity in female catfish Rhamdia quelen. Physiol Behav. 2014;128:232-236.

Baroiller JF, Guiguen Y, Fostier A. Endocrine and environmental aspects of sex differentiation in fi sh. Cell. Mol. Life Sci. 1999;55:910-931.

Baroiller JF, D'Cotta H. Environment and sex determination in farmed fish. Comp. Biochem. Physiol. C. 2001;130:399-409.

Baroiller JF, D'Cotta H, Bezault E, Wessels S, Hoerstgen-Schwark G. Tilapia sex determination: where temperature and genetics meet. Comp Biochem Physiol A. 2009;153:30-38

Baroiller JF, D'Cotta H, Shved N, Berishvili G, Toguyeni A, Fostier A, Reinecke M. Oestrogen and insulin-like growth factors during the reproduction and growth of the tilapia Oreochromis niloticus and their interactions. Gen Comp Endocrinol. 2014;205:142-150.

Biswas S, Jadhao AG, Pinelli C, Palande NV, Tsutsui K. GnIH and $\mathrm{GnRH}$ expressions in the central nervous system and pituitary 
of Indian major carp, Labeo rohita during ontogeny: an immunocytochemical study. Gen Comp Endocrinol. 2015;220:88-92.

Brown EE, Baumann H, Conover DO. Temperature and photoperiod effects on sex determination in a fish. J Exp Mar Bio Ecol. 2014;461:39-43

Budd AM, Banh QQ., Domingos JA \& Jerry DR. Approaches, challenges and opportunities for Aquaculture. J Mar Sci Eng. 2015;3:329-355.

Bubser M, Fadel JR, Jackson LL, Meador-Woodruff JH, Jing D, Deutch AY. Dopaminergic regulation of orexin neurons. Eur J Neurosci. 2005;21:2993-3001.

Cain KE, Pryke SR. Testosterone production in response to exogenous gonadotropin releasing hormone (GnRH challenge) depends on social environment and color polymorphism. Gen Comp Endocrinol. 2017;244:77-85.

Carrillo M, Espigares F, Felip A, Escobar S, Molés G, Rodríguez R, Zanuy S. Updating control of puberty in male European sea bass: a holistic approach. Gen Comp Endocrinol. 2015;221:42-53.

Chen T, Chen S, Ren C, Hu C, Tang D, Yan A. Two isoforms of leptin in the White-clouds Mountain minnow (Tanichthys albonubes): Differential regulation by estrogen despite similar response to fasting. Gen Comp Endocrinol. 2016;225:174-184.

Chi ML, Wen HS, Ni M, He F, Li JF, Qian K, Yin XH. Molecular identification of genes involved in testicular steroid synthesis and characterization of the responses to hormones stimulation in testis of Japanese sea bass (Lateolabrax japonicas). Steroids. 2014:84:92-102.

Chun-Wei F, Peter Koopman, JB. Control of mammalian germ cell entry into meiosis. Mol Cell Endocrinol. 2014;382:488-497.

Cnaani A, McLean E, Hallerman EM. Effects of growth hormone transgene expression and triploidy on acute stress indicators in Atlantic salmon (Salmo salar L.). Aquaculture. 2013;412:107-116.

Coumailleau P, Pellegrini E, Adrio F, Diotel N, Cano-Nicolau J, Nasri A, Kah O. Aromatase, estrogen receptors and brain development in fish and amphibians. Biochimica et Biophysica Acta (BBA)-Gene Regulatory Mechanisms, 2015;1849(2):152-162.

de Roux N, Genin E, Carel JC, Matsuda F, Chaussain JL, Milgrom E. 2003. Hypogonadotropic hypogonadism due to loss of function of the KiSS1-derived peptide receptor GPR54. Proc. Natl. Acad. Sci. U.S.A. 100, 10972-10976.

Devlin RH \& Nagahama Y. Sex determination and sex differentiation in fish: an overview of genetic, physiological, and environmental influences. Aquaculture. 2002;208(3-4):191-364.

Descamps S, Gilchrist HG, Bety J, Buttler El, Forbes MR. Costs of reproduction in a long-lived bird: large clutch size is associated with low survival in the presence of a highly virulent disease. Biol Lett. 2009;5(2):278-281.

Diemer O, Bittencourt F, Barcellos LG, Boscolo WR, Feiden A, Romagosa E. Lysine in the diet of Rhamdia voulezi male broodstocks confined in net cages. Aquaculture. 2014;434:93-99.

Dutil JD, Lambert Y. Natural mortality from poor condition in Atlantic cod (Gadus morhua). Can J Fish Aquat Sci. 2000;57(4):826-836.
Escobar S, Servili A, Espigares F, Gueguen MM, Brocal I, Felip A, Kah $O$. Expression of kisspeptins and kiss receptors suggests a large range of functions for kisspeptin systems in the brain of the European sea bass. PloS one, 2013;8(7):e70177.

Escobar S, Felip A, Salah M, Zanuy S, Carrillo M. Long-term feeding restriction in prepubertal male sea bass (Dicentrarchus labrax L.) increases the number of apoptotic cells in the testis and af fects the onset of puberty and certain reproductive parameters. Aquaculture. 2014;433:504-512.

Escobar S, Rocha A, Felip A, Carrillo M, Zanuy S, Kah O, Servili A. Leptin receptor gene in the European sea bass (Dicentrarchus labrax): cloning, phylogeny, tissue distribution and neuroanatomical organization. Gen Comp Endocrinol. 2016;229:100-111.

Fairgrieve MR, Shibata Y, Smith EK, Hayman ES, Luckenbach JA. Molecular characterization of the gonadal kisspeptin system: cloning, tissue distribution, gene expression analysis and localization in sablefish (Anoplopoma fimbria). Gen Comp Endocrinol. 2016;225:212-223.

Ferrandino I, Monaco A, Grimaldi, MC. 2015. Effects of leptin on FSH cells in the pituitary gland of Podarcis siculus. Comptes rendus biologies, 338(3), 180-184.

Franz AC, Faass O, Köllner B, Shved N, Link K, Casanova A, Reinecke $M$. Endocrine and local IGF-I in the bony fish immune system. Biology. 2016;5(1):9.

González A, Fernandino Jl, Somoza GM. Effects of $5 \alpha$-dihydrotestosterone on expression of genes related to steroidogenesis and spermatogenesis during the sex determination and differentiation periods of the pejerrey, Odontesthes bonariensis. Comp Biochem Physiol A Mol Integr Physiol.2015;182:1-7.

Gorissen M, Flik G. Leptin in teleostean fish, towards the origins of leptin physiology. J Chem Neuroanat. 2014;(61-62):200-206.

Gopurappilly R, Ogawa S, Parhar IS. Functional significance of $\mathrm{GnRH}$ and kisspeptin, and their cognate receptors in teleost reproduction. Front Endocrinol. 2013;4:24.

Grier HJ, Uribe-Aranzábal MC. 2009. The testis and spermatogenesis teleost. In: Jamieson BMG (Ed.). Reproductive biology and phylogeny of fishes (Agnathans and Neotelestomi). Phylogeny -Reproductive System Viviparity - Spermatozoa. Enfield: Science Publisher. p.119-142.

Guzmán JM, Luckenbach JA, da Silva DA, Ylitalo G, Swanson P. Development of approaches to induce puberty in cultured female sablefish (Anoplopoma fimbria). Gen Comp Endocrinol. 2015;221:101-113.

Heule C, Göppert C, Salzburger W, Böhne A. Genetics and timing of sex determination in the East African cichlid fish Astatotilapia burtoni. BMC genetics. 2014;15(1):140.

Horie Y, Shimizu A, Adachi S, Kobayashi T. Expression and localization of gonadotropic hormone subunits (Gpa, Fshb, and Lhb) in the pituitary during gonadal differentiation in medaka. Gen Comp Endocrinol. 2014;204:173-180.

Hussain MA, Song WJ, Wolfe A. There is Kisspeptin - And Then There is Kisspeptin. Trends Endocrinol Metab. 2015;26(10):564 572.

Determinación, diferenciación sexual y pubertad en peces 
Ikegami T, Takeuchi Y, Hur SP, Takemura A. Impacts of moonlight on fish reproduction. Mar Genomics. 2014;14:59-66.

Joy KP, Chaube R. Vasotocin-A new player in the control of oocyte maturation and ovulation in fish. Gen Comp Endocrinol. 2015;221:54-63.

Kaneko H, ljiri S, Kobayashi T, Izumi H, Kuramochi Y, Wang DS, Nagahama Y. Gonadal soma-derived factor (gsdf), a TGF-beta superfamily gene, induces testis differentiation in the teleost fish Oreochromis niloticus. Mol Cell Endocrinol. 2015;415:87-99.

Labbe C, Robles V, Herraez MP. Epigenetics in fish gametes and early embryo. Aquaculture. 2017;427:93-106.

Li CG, Wang H, Chen HJ, Zhao Y, Fu PS, Ji XS. Differential expression analysis of genes involved in high-temperature induced sex differentiation in Nile tilapia. Comp Biochem Physiol B Biochem Mol Biol. 2014;177:36-45.

Liu Q, Chen Y, Copeland D, Ball H, Duff RJ, Rockich B, Londraville RL. Expression of leptin receptor gene in developing and adult zebrafish. Gen Comp Endocrinol. 2010;166(2):346-355.

Liu XY, Zhang XB, Li MH, Zheng SQ, Liu ZL, Cheng YY, Wang DS. Genome-wide identification, evolution of chromobox family genes and their expression in Nile tilapia. Comp Biochem Physiol B Biochem Mol Biol. 2017;203:25-34.

Lomniczi A, Wright H, Ojed SR. Epigenetic regulation of female puberty. Front Neuroendocrinol. 2015;36:90-107.

López JM, Sanz-Morello B, González A. Organization of the orexin/ hypocretin system in the brain of two basal actinopterygian fishes, the cladistians Polypterus senegalus and Erpetoichthys calabaricus. Peptides. 2014;61:23-37.

Luzio A, Santos D, Fontaínhas-Fernandes AA, Monteiro SM, Coimbra AM. Effects of $17 \alpha$-ethinylestradiol at different water temperatures on zebrafish sex differentiation and gonad development. Aquat Toxicol. 2016;174:22-35.

Martins RS, Pinto PI, Guerreiro PM, Zanuy S, Carrillo M, Canário AV. Novel galanin receptors in teleost fish: identification, expression and regulation by sex steroids. General and comparative endocrinology, 2014;205:109-120.

Matsuda M, Sakaizumi M. Evolution of the sex-determining gene in the teleostean genus Oryzias. Gen Comp Endocrinol. 2016;239:80-88.

Mazón MJ, Molés G, Rocha A, Crespo B, Lan-Chow-Wing O, Espigares F, Gómez A. Gonadotropins in European sea bass: endocrine roles and biotechnological applications. Gen Comp Endocrinol. 2015;221:31-41.

Mazzeo I, Peñaranda DS, Gallego V, Baloche S, NourizadehLillabadi R, Tveiten H, Pérez L. Temperature modulates the progression of vitellogenesis in the European eel. Aquaculture. 2014;434:38-47.

Metzger DCH, Shulte PM. Epigenomics in marine fishes. Mar Genomics. 2016;30:43-54.

Minkina A, Matson CK, Lindeman RE, Ghyselinck NB, Bardwell VJ, Zarkower D. DMRT1 protects male gonadal cells from retinoid-dependent sexual transdifferentiation. Dev Cell. 2014;29(5):511-520.

Muñoz-Cueto JA. 2009. Cerebro y reproducción en peces: bases neurales y neuroendocrinas. En: M. Carrillo (Ed.). Reproducción en acuicultura (pp. 27-96). Observatorio Español de Acuicultura, Consejo Superior de Investigaciones Científicas y Ministerio de Agricultura, Pesca y Alimentación.

Nelson JS, Grande T, Wilson MVH. 2016. Fishes of the world. Fifth edition. John Wiley \& Sons, Hoboken, 707 pp.

Pandit NP, Bhandari RK, Kobayashi Y, Nakamura M. High temperature-induced sterility in the female Nile tilapia, Oreochromis niloticus. Gen Comp Endocrinol. 2015;213:110-117.

Park HK, Ahima RS. Physiology of leptin: energy homeostasis, neuroendocrine function and metabolism. Metabolism. 2015;64(1):24-34.

Penman DJ, Piferrer F. Fish gonadogenesis. Part 1. Genetic and environmental mechanisms of sex determination. Rev Fish Sci. 2008;16(S1):16-34.

Pfennig F, Standke A, Gutzeit HO. The role of Amh signaling in teleost fish - Multiple functions not restricted to the gonads. Gen Comp Endocrinol. 2015;223:87-107.

Piferrer F, Guiguen Y. Fish gonadogenesis. Part 2. Molecular biology and genomics of sex differentiation. Rev Fish Sci. 2008;16(S1):35-55.

Piferrer F. 2009. Determinación y diferenciación sexual de los peces. En: M. Carrillo (Ed.). Reproducción en acuicultura (pp. 249336). Observatorio Español de Acuicultura, Consejo Superior de Investigaciones Científicas y Ministerio de Agricultura, Pesca y Alimentación.

Piferrer F, Blázquez M. Aromatase distribution and regulation in fish. Fish Physiol Biochem. 2005;31(2-3):215.

Plant TM. Neuroendocrine control of the onset of puberty. Front Neuroendocrinol. 2015;38:73-88.

Rhody NR, Davie A, Zmora N, Zohar Y, Main KL, Migaud H. Influence of tidal cycles on the endocrine control of reproductive activity in common snook (Centropomus undecimalis). Gen Comp Endocrinol. 2015;224:247-259.

Ribas L, Robledo D, Gómez-Tato A, Viñas A, Martínez P, Piferrer F. Comprehensive transcriptomic analysis of the process of gonadal sex differentiation in the turbot (Scophthalmus maximus). Mol Cell Endocrinol. 2016;422:132-149.

Sadovy Y, Shapiro DY. 1987. Criteria for the diagnosis of hermaphroditism in fishes. Copeia: 136-156.

Sanchez-Garrido M., Tena-Sempere M. Metabolic controlo $f$ puberty: Roles of leptina and Kisspeptins. Horm Behav. 2013;64(2):187-194.

Santi S, Gennotte V, Toguyeni A, Mélard C, Antoine N, Rougeot C. Thermosensitivity of the sex differentiation process in the African catfish, Clarias gariepinus: Determination of the thermosensitive period. Aquaculture. 2016;455:73-80. 
Schulz RW, De França LR, Lareyre JJ, LeGac F, Chiarini-Garcia H, Nobrega RH, Miura T. Spermatogenesis in fish. Gen Comp Endocrinol. 2010;165(3):390-411.

Seminara SB, Messager S, Chatzidaki EE, Thresher RR, Acierno Jr JS, Shagoury JK, Bo-Abbas Y, Kuohung W, Schwinof KM, Hendrick AG, Zahn D, Dixon J, Kaiser UB, Slaugenhaupt SA, Gusella JF, O'Rahilly S, Carlton MB, Crowley Jr WF, Aparicio SA, Colledge $\mathrm{WH}$. The GPR54 gene as a regulator of puberty. N. Engl. J Med. 2003;349:1614-1627.

Schaefer FJ, Wuertz S. Insights into kisspeptin-and leptin-signalling on GnRH mRNA expression in hypothalamic organ cultures of immature pikeperch Sander lucioperca. Int Aquat Res. 2016;8(2):191-196.

Su B, Peatman E, Shang M, Thresher R, Grewe P, Patil J, Duncan PL. Expression and knockdown of primordial germ cell genes, vasa, nanos and dead end in common carp (Cyprinus carpio) embryos for transgenic sterilization and reduced sexual maturity. Aquaculture. 2014;420:S72-S84.

Su B, Shang M, Grewe PM, Patil JG, Peatman E, Perera DA, Liu Z. Suppression and restoration of primordial germ cell marker gene expression in channel catfish, Ictalurus punctatus, using knockdown constructs regulated by copper transport protein gene promoters: Potential for reversible transgenic sterilization. Theriogenology. 2015;84(9):1499-1512.

Tokarz J, Möller G, de Angelis MH, Adamski J. Steroids in teleost fishes: a functional point of view. Steroids. 2015;103:123144

Trippel EA, Butts IA, Babin A, Neil SR, Feindel NJ, Benfey TJ. Effects of reproduction on growth and survival in Atlantic cod, Gadus morhua, assessed by comparison to triploids. J Exp Mar Bio Ecol. 2014;451:35-43.
Tzung KW, Goto R, Saju JM, Sreenivasan R, Saito T, Arai K, Orbán, L. Early depletion of primordial germ cells in zebrafish promotes testis formation. Stem Cell Reports. 2015;4(1):61-73.

Valentin F.N. 2013. Processo de diferenciação gonadel em Pseudoplatystoma fasciatum e tentativa de feminizacao com 17ß-estradiol

Vandeputte M, Dupont-Nivet M, Chavanne H, Chatain B. A polygenic hypothesis for sex determination in the European sea bass Dicentrarchus labrax. Genetics. 2007;176:1049-1057.

Wang HP, Gao ZX, Rapp D, O'Bryant P, Yao H, Cao XJ. Effects of temperature and genotype on sex determination and sexual size dimorphism of bluegill sunfish Lepomis macrochirus. Aquaculture. 2014;420:S64-S71.

Weil C, Le Bail PY, Sabin N, Le Gac F. In vitro action of leptin on FSH and $\mathrm{LH}$ production in rainbow trout (Onchorhychus mykiss) at different stages of the sexual cycle. Gen Comp Endocrinol. 2003;130:2-12.

Weltzien FA, Hildahl J, Hodne K, Okubo K, Haug TM. Embryonic development of gonadotrope cells and gonadotropic hormones-lessons from model fish. Mol Cell Endocrinol. 2014;385(12):18-27.

Wong $\pi$, Zohar Y. Production of reproductively sterile fish by a nontransgenic gene silencing technology. Sci Rep. 2015;5:15822.

Yildirim S, Vardar $\mathrm{H}$. The influence of a longer photoperiod on growth parameters of European sea bass Dicentrarchus labrax (Linnaeus, 1758) reared in sea cages. J Appl Ichthyol. 2015;31(1):100-105

Zhang Z, Lau SW, Zhang L, Ge W. Disruption of zebrafish follicle-stimulating hormone receptor (fshr) but not luteinizing hormone receptor (lhcgr) gene by TALEN leads to failed follicle activation in females followed by sexual reversal to males. Endocrinology, 2015;156(10):3747-3762. 